Mots. Les langages du politique

\title{
Bibliographie de lexicologie sociopolitique
}

\section{(2) OpenEdition \\ Journals}

Édition électronique

URL : https://journals.openedition.org/mots/2743

DOI : $10.4000 /$ mots. 2743

ISSN : 1960-6001

Éditeur

ENS Éditions

\section{Édition imprimée}

Date de publication : 1 novembre 2004

Pagination : 143-145

ISBN : 2-84788-064-X

ISSN : 0243-6450

\section{Référence électronique}

"Bibliographie de lexicologie sociopolitique », Mots. Les langages du politique [En ligne], 76 | 2004, mis en ligne le 01 avril 2009, consulté le 22 avril 2022. URL : http://journals.openedition.org/mots/2743 ; DOI : https://doi.org/10.4000/mots.2743 


\section{Bibliographie de lexicologie sociopolitique}

AGOSTINO M. et al., 1987, Textes d'histoire contemporaine, Bordeaux, Presses universitaires, $200 \mathrm{p}$.

AMOSSY R. et MAINGUENEAU D. (dir.), 2004, L'analyse du discours : un tournant dans les études littéraires ?, Toulouse, Presses universitaires du Mirail, 488 p.

AMOSSY R. et KOREN R. (dir.), 2004, Semen, n $^{\circ}$ 17, février, Argumentation et prise de position : pratiques discursives, $190 \mathrm{p}$.

AUTHIER-REVUZ J., DOURY M. et REBOUL-TOURÉ S. (dir.), 2004, Parler des mots. Le fait autonymique en discours, Paris, Presses de la Sorbonne nouvelle, $382 \mathrm{p}$.

BENDER-BERLAND G., KRAMER J. et REISDCERFER J., 2003, Dictionnaire étymologique des éléments français du luxembourgeois. Fascicule 1 (Abat-jour-Assürance), Tübingen, Gunter Narr Verlag, 80 p.

ELOY J.-M. (éd.), 2004, Des langues collatérales. Problèmes linguistiques, sociolinguistiques et glottopolitiques de la proximité linguistique, Paris, L'Harmattan, 283 p. BOULANGER J.-C., 2003, Les inventeurs de dictionnaires. De l'eduba des scribes mésopotamiens au scriptorum des moines médiévaux, Ottawa, Presses de l'université, $545 \mathrm{p}$.

— 2004, Manuel-exemplier d'histoire de la langue française, Québec, Université Laval, $185 \mathrm{p}$.

CALVET L.-J. et MATHIEU P. (dir.), 2003, Marges linguistiques, $\mathrm{n}^{\circ}$ 6, novembre, Argots, «français populaires » et langues populaires, $198 \mathrm{p}$.

CHEBEL M., 1995, Dictionnaire des symboles musulmans, Paris, Albin Michel, 504 p.

CORMIER M.-C., FRANCCEUR A. et BOULANGER J.-C. (dir.), 2004, Les dictionnaires Le Robert. Genèse et évolution, Montréal, Presses de l'université de Montréal, $302 \mathrm{p}$.

DANBLON E., 2002, Rhétorique et rationalité. Essai sur l'émergence de la critique et de la persuasion, Bruxelles, Éditions de l'ULB, 276 p.

- 2004, Argumenter en démocratie, Bruxelles, Labor, 96 p.

DANGEL J., DECLERCQ G. et MURAT M. (textes réunis par), 2003, La parole polémique, Paris, Champion, $549 \mathrm{p}$.

DELON M. (dir.), 1997, Dictionnaire européen des Lumières, Paris, PUF, 1160 p. 
DERVILLE G. et PIONCHON S., 2004, Les femmes et la politique, Grenoble, Presses universitaires de Grenoble, $216 \mathrm{p}$.

DUCARD D., 2002, La voix et le miroir. Une étude sémiologique de l'imaginaire et de la formation de la parole, Paris, L'Harmattan, $276 \mathrm{p}$.

— 2004, Entre grammaire et sens. Études sémiologiques et linguistiques, Paris, Ophrys, $208 \mathrm{p}$.

FERENCZI T., 2004, La politique en France. Dictionnaire historique de 1870 à nos jours, Paris, Le Monde-Larousse, $479 \mathrm{p}$.

GUILLIEN R., GUINCHARD V. et al., 2003, Lexique des termes juridiques, 14édition revue et mise à jour, Paris, Dalloz, $619 \mathrm{p}$.

HÄRMÄ J. (textes réunis par), 2003, Le langage des médias : discours éphémères?, Paris, L'Harmattan, $173 \mathrm{p}$.

HERMÈS, $n^{\circ}$ 38, mai 2004, Les sciences de l'information et de la communication. Savoirs et pouvoirs, $256 \mathrm{p}$.

HETZEL A.-M., 2004, «Les mots, miroirs de l'identité ? Chronique linguistique », Baugnet L. (dir.), Constructions identitaires et dynamiques politiques, Bruxelles, PIEPeter Lang, p. 213218.

KARAFIÁTH J. et ROPARS M.-C. (dir.), 2004, Pluralité des langues et mythe du métissage. Parcours européen, Paris, Presses universitaires de Vincennes, 206 p.

KLEIN J. et MONTBRIAL de T. (dir.), 2000, Dictionnaire de stratégie, Paris, PUF, 624 p.

LAURIAN A.-M. (dir.), 2003, La langue libérée. Études de socio-lexicologie, Bruxelles, PIE-Peter Lang, $244 \mathrm{p}$.

LEFÈVRE J., 2004, «De l'univers lexical de travailleurs à celui de salariés. La CFDT de 1970 à 1998 : évolution d'un parcours identitaire», Baugnet L. (dir.), Constructions identitaires et dynamiques politiques, Bruxelles, PIE-Peter Lang, p. 192211.

LUCKEN C. et SÉGUY M. (dir.), 2004, Médiévales, $n^{\circ} 45$, Grammaire du vulgaire. Normes et variations de la langue française, $188 \mathrm{p}$.

MALMORG von G., 2004, La spécificité de la métaphore journalistique : les métaphores de quelques champs génériques dans Le Monde et L'Express. Analyse thématique, comparative et distributive, Cahiers de la recherche (département de français et d'italien, université de Stockholm), n² 25, $266 \mathrm{p}$.

MARCHETTI D. (dir.), 2004, En quête d'Europe. Médias européens et médiatisation de l'Europe, Rennes, Presses universitaires de Rennes, 304 p.

MOLLARD-DESFOUR A., 2004, Le dictionnaire des mots et expressions de couleur : le bleu, nouvelle édition, Paris, CNRS, 274 p.

MÜNCHOW von P., 2004, Les journaux télévisés en France et en Allemagne. Plaisir de voir ou devoir de s'informer?, Paris, Presses de la Sorbonne nouvelle, 256 p.

OLIVESI S., 2004, Questions de méthode : une critique de la connaissance pour les sciences de la communication, Paris, L'Harmattan, 148 p.

PERGNIER M., 2004, La désinformation par les mots, Paris, Éditions du Rocher, 251 p. 
PRÉVOST J.-P., 2004, Nouveau vocabulaire biblique, Paris, Bayard-Médiaspaul, 480 p. RAMONET I., 2001, La tyrannie de la communication, Paris, Gallimard, 304 p.

RINGOOT R. et ROBERT-DEMONTROND P. (dir.), 2004, L'analyse de discours, Rennes, Éditions Apogée, 222 p.

ROMAN J., 1996, Chronique des idées contemporaines, Paris, Éditions Bréal, 1020 p. - 1998, La démocratie des individus, Paris, Calmann-Lévy, 240 p.

THÉRENTY M.-E. et VAILLANT A., 2001, 1836, l'an de l'ère médiatique. Analyse littéraire et historique de La Presse de Girardin, Paris, Nouveau Monde éditions, 386 p. VALLET O., 2004, Petit lexique des guerres de religion d'hier et d'aujourd'hui, Paris, Albin Michel, $161 \mathrm{p}$.

WARESQUIEL de E., 1999, Le siècle rebelle. Dictionnaire de la contestation au $20^{e}$ siècle, Paris, Larousse, 672 p. 